\title{
ADJUSTMENT OF A REGIONAL ALTIMETRIC NETWORK, IN BRAZIL, TO ESTIMATE NORMAL HEIGHTS AND GEOPOTENTIAL NUMBERS
}

\author{
Giuliano Sant'Anna Marotta ${ }^{1}$ - ORCID: 0000-0003-1073-0683 \\ ${ }^{1}$ Universidade de Brasília, Instituto de Geociências, Observatório Sismológico, Brasília - DF, Brasil. \\ E-mail: marota@unb.br
}

Received in $11^{\text {th }}$ February 2019

Accepted in $13^{\text {th }}$ December 2019

\begin{abstract}
:
In 2018, the Brazilian Institute of Geography and Statistics (IBGE) defined the normal height values and geopotential numbers for the High Precision Altimetric Network (HPAN), creating the need for developing procedures able to adapt works correlated with the Brazilian Geodetic System (BGS). In that context, and considering the state and municipal altimetric networks, it is necessary to estimate normal heights. To this end, this paper proposes to estimate normal height values and geopotential numbers for the Altimetric Network of the Federal District (AN-DF). Computational procedures involving the Least Squares Method were established and applied in a geometric levelling survey, which includes 200 stations distributed throughout the study area. The obtained results allowed estimating the normal heights of the network stations with accuracy up to $0.032 \mathrm{~m}$. However, because significant differences were found in the adjusted and known values of some used HPAN stations, we recommend a rigorous analysis of these stations before using them. In any case considering that the geometric levelling and the applied procedures were carried out correctly, it is suggested that the values estimated for all stations of the AN-DF in this work may be used.
\end{abstract}

Keywords: Geopotential numbers; Normal heights; Regional altimetric network.

How to cite this article: MAROTTA, G. S. Adjustment of a regional altimetric network, in Brazil, to estimate normal heights and geopotential numbers. Bulletin of Geodetic Sciences. 26(1): e2020002, 2020 


\section{Introduction}

The High Precision Altimetric Network (HPAN) belongs to the Brazilian Geodetic System (BGS) and is maintained by the Brazilian Institute of Geography and Statistics (IBGE). This network covers the entire Brazilian territory, having nowadays two vertical datums, Imbituba and Santana, and continuous data collection via geometric leveling technique, where new stations are implanted. Therefore, to incorporate new stations into the HPAN, all stations in the network adjustment are used to estimate and/or update their heights using the Least Squares Method (LSM).

Like the HPAN, a Gravimetric Network (GN), which also belongs to the BGS, has been continually updated, with the acquisition of new gravimetric data. At first, the GN was developed to enable and improve the computation of geoid heights. However, to give a physical meaning to the heights, new gravimetric data are being acquired, mainly in the HPAN stations. As a result, the IBGE published new heights, now called normal heights, for the HPAN stations in 2018 (IBGE 2018), where gravimetric observations were included in the functional model for the network adjustment, following the recommendations of the International Association of Geodesy (IAG).

The HPAN update is in agreement with the works performed in many parts of the world. In this context, Freitas and Blitzkow (1999) promoted a reflection on the physical meaning of height, the problems and the practical solutions that can be implemented to define a vertical datum for the Geocentric Reference System for the Americas (SIRGAS). Drewes et al. (2002) showed that height type, reference surface, realization and maintenance of the reference system are presented as main topics for defining the vertical reference system for SIRGAS, and recommended introducing two height types, the geometric (ellipsoidal) and normal (physical). Luz (2004) investigated the possibility of using gravimetric data to define the physical heights in Brazil and to connect them with the South American Height Systems associated with SIRGAS. To contribute with the integration of the Brazilian vertical network into the global height system, Palmeiro and Freitas (2010) developed a methodology to measure/ determine the physical heights by computing the geopotential numbers using the Geographical Information System to integrate the BGS information. Severo et al. (2013) determined and evaluated the corrections of different physical heights (dynamics, normal and orthometric) in a leveling belonging to HPAN, located in the northeastern Rio Grande do Sul. Also, Luz (2016) reviewed the main concepts related to vertical geodetic reference systems and physical heights, to prepare the first HPAN adjustment considering the geopotential differences.

Considering the exposition and also that states and cities in Brazil have their geodetic networks referred to the BGS, they need to be updated for each new adjustment and/or change in the national geodetic network. Therefore, it is necessary to establish procedures for estimating normal heights for these networks. Consequently, this research aims at developing a procedure to adjust the Altimetric Network of the Federal District (AN-DF), Brazil, and to estimate the normal heights and the geopotential numbers to be associated with the BGS.

\section{Normal Height and Geopotential Number}

Normal heights $\left(H_{N}\right)$ can be characterized as a type of physical height $\left(H_{F}\right)$ since they are associated with the terrestrial gravity field $(g)$. Therefore, this height can be expressed by the geopotential number $\left(C_{P}\right)$, defined as the difference between the gravity potential on geoid level $\left(W_{0}\right)$ and the gravity potential at the point $\left(W_{P}\right)$ considered. This relationship can be expressed as (Torge 1991; Freitas and Blitzkow 1999; Gemael 1999; Luz 2016; IBGE 2018):

$$
C_{P}=W_{0}-W_{P}=-\int_{0}^{P} d W=\int_{0}^{P} g \cdot d H
$$

In practice, height is determined by surveys involving geometric leveling technique and, therefore, Equation 1 must be expressed by a discrete model. Then, considering a finite sum of sections of height differences $(\Delta H)$, with 
the average gravity values $(\bar{g})$ observed for each section, we have (Gemael 1999):

$$
C_{P}=W_{0}-W_{P} \approx \sum_{i=1}^{n} \bar{g}_{i} \cdot \Delta H_{i}
$$

Due to propagation errors on the geometric leveling technique to compute heights, Luz (2016) and IBGE (2018) suggested that is preferable to compute geopotential differences $\left(\Delta C_{A B}\right)$, for a small distance between points ( $A$ and $B$ ). It allows geopotential numbers $(C)$ to be computed adjusting the observations of these differences $(\Delta C)$, because:

$$
\Delta C_{A B}=C_{B}-C_{A}=-\left(W_{B}-W_{A}\right) \approx \bar{g}_{A B} \cdot \Delta H_{A B}
$$

According to Torge (1991), $C$ describes better the behavior of masses in the gravity field and could be used in several applications, such as hydraulic engineering and oceanography. However, $C$ contradicts the demand for a height system that works on the metric unit. In this case, the physical height $\left(H_{F}\right)$ can be expressed as (Freitas and Blitzkow 1999; Torge 1991; Gemael 1999; Severo et al. 2013; Luz 2016; IBGE 2018):

$$
H_{F}=\frac{C}{G}
$$

Considering a height using the geoid as a reference, we have an orthometric height $(H)$ as definition while $G$ (Equation 4) must represent the average gravity measured along the plumb line (Figure 1). Thus, becoming necessary to know the gravity values inside the Earth. However, $H$ can not be precisely estimated as the density distribution in the Earth interior is not known.

As an alternative to solve the problem for determining $H$, IBGE (2018) in consonance with Drewes et al. (2002), defined the use of normal heights $\left(H_{N}\right)$, according to the definitions established by SIRGAS. In this case, Equation 4 can be expressed as:

$$
H_{N}=\frac{C}{\gamma_{v}}
$$

$\gamma_{v}$ represents the normal gravity average value, along the vertical (Figure 1), and can be expressed as (Heiskanen and Moritz 1967; Luz 2016; IBGE 2018):

$$
\begin{gathered}
\gamma_{v}=\gamma_{0} \cdot\left[1-\frac{H_{N}}{a} \cdot\left(1+f+m-2 \cdot f \cdot \sin ^{2} \varphi\right)+\left(\frac{H_{N}}{a}\right)^{2}\right] \\
\gamma_{0}=\gamma_{a} \cdot \frac{1+k \cdot \sin ^{2} \varphi}{\sqrt{1-e^{2} \cdot \sin ^{2} \varphi}} \\
k=\frac{b \cdot \gamma_{b}-a \cdot \gamma_{a}}{a \cdot \gamma_{a}} \\
m=\frac{\omega^{2} \cdot a^{2} \cdot b}{G M}
\end{gathered}
$$

$\varphi$ and $H_{N}$ are the geodetic latitude and the normal height of a point of interest; $a, b, e$ and $f$ are the major and minor axes, the first eccentricity and flattening, respectively; $\gamma_{a}, \gamma_{b}$ and $\gamma_{0}$ are the normal gravity on the equator, pole and the point considered, respectively; and $\omega$ and $G M$ are the angular velocity and the geocentric gravitational constant. All parameters are associated with the adopted reference ellipsoid.

Given the above, according to Figure 1 and IBGE (2018), $\gamma_{v}$ is the normal gravity average value along the vertical, $H_{N}$ is measured along the so-called normal vertical direction and, because it does not consider the real Earth, the height does not refer to the geoid, but to the quasi-geoid. 


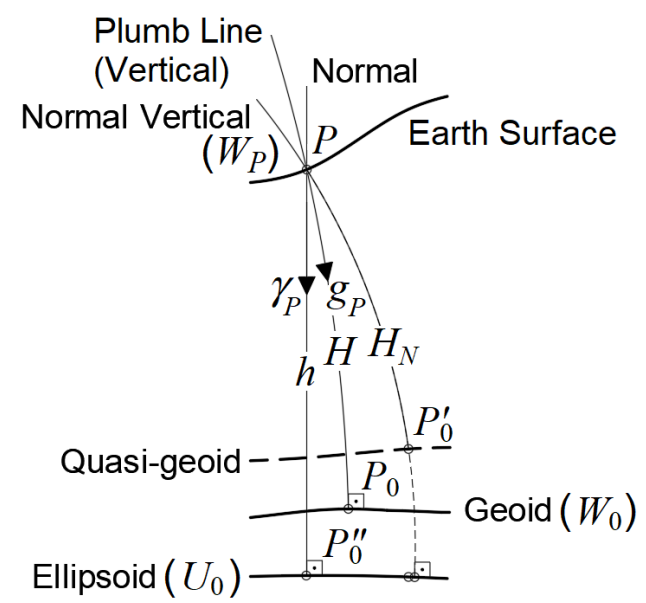

Figure 1: Geometric $(h)$, orthometric $(H)$ and normal $\left(H_{N}\right)$ heights at point $P$. Adapted from Torge (1991), Freitas and Blitzkow (1999) and IBGE (2018).

\section{Altimetric Network Adjustment and Evaluation}

According to Equations 2 and 3, $C$ as a parameter to be estimated can be used to compute the physical height, since $\Delta H$ and $\bar{g}$ are considered observed values. Subsequently, $H_{N}$ can be estimated by Equation 5 .

In this research $H_{N}$ values were estimated by a functional model defined by developing the Equations 3 and 5 and then $C$ values were computed by Equation 3. Therefore, the functional model considering geometric leveling and gravimetric observations for distinct points $(A$ and $B$ ), can be expressed as:

$$
F(X)=\Delta H_{A B}=\frac{H_{V_{B}} \gamma_{V_{B}}-H_{X_{A}} \%_{A}}{\bar{g}_{A B}}
$$

The estimation of the parameters in Equation 10, using the Constrained LSM (CLSM), considers the following:

$$
\Delta H_{A B}=L_{b}+V=F\left(X_{0}+X\right)=F\left(X_{a}\right) \mid \sum_{i=1}^{n} V_{i}^{2} \rightarrow 0
$$

where, $L_{b}$ is the vector of observed values $\left(\Delta H_{A B}\right) ; V$, the vector of residual values; $X_{0}$, the vector of initial parameters; $X$, vector of corrections; and $X_{a}$, vector of adjusted parameters.

For the CLSM, the condition equations refer to the normal heights of stations used as reference $\left(H_{N_{R E F}}\right)$. Therefore, $X$ can be expressed as (Gemael, 1999):

$$
X=-\left(A^{T} P A+C_{C}^{T} P_{C} C_{C}\right)^{-1}\left(A^{T} P L+C_{C}^{T} P_{C} \varepsilon_{C}\right)
$$

where, $A$ and $C_{C}$ are the matrices of partial differential equations, which consider the functional model and the condition equations (functional model of injunction) related to the parameters, respectively; $L$, vector of the differences between the computed $\left(L_{0}\right)$ and observed $\left(L_{b}\right)$ values; $P$ and $P_{C}$ are the weight matrices of the observed and reference (injunction) values, respectively; and the $\varepsilon_{C}$, the closure error vector of the model.

As demonstrated in Equations 5, 6 and 10, $H_{N}$ and $\gamma_{v}$ are interdependent. Therefore, it is necessary to develop the adjustment by LSM involving an interactive process, until the a priori and a posteriori $H_{N}$ values are not significantly different. The heights $(H)$ used a priori, both for defining the initial parameter vectors, and for determining $\gamma_{v}, H_{N}$ and $\Sigma_{H_{N}}$ (uncertainties), are derived from the direct computation of the leveling circuits (Equation 13), involving $H_{N}$ values of the reference stations. 


$$
H=H_{N_{R E F}}+\sum_{i=1}^{n} \Delta H_{i}
$$

The weights of the geometric leveling observations are defined, considering the nominal accuracy $(\sigma)$ of the equipment used and the distance $(D)$ between each observation section of height difference, to compute the variance of the observed values $\left(\Sigma_{\Delta H}\right)$. It can be expressed as:

$$
\Sigma_{\Delta H}=\left(\sigma \cdot \sqrt{D_{k m}}\right)^{2}
$$

Considering a regional network, the variance $\left(\Sigma_{H_{N_{R E F}}}\right)$ close to zero was defined for the stations used as a reference. In this case, these stations were considered local vertical datums defined in the study area.

To evaluate the results of this research, we analyzed: the $\Sigma_{H_{N}}$, estimated after applying the a posteriori variance factor in the weight matrix; the differences between the estimated and known $H_{N}$ values in stations adopted as verification; the a posteriori variance factor $\left(\hat{\sigma}_{0}^{2}\right)$ using the Chi-square $\left(\chi^{2}\right)$ test, and the a posteriori standardized residual ( $V_{i} / \sigma_{V_{i}}$ ) using the Tau $(\tau)$ test, both according to Cross (1983).

\section{Computing the Normal Heights and the Geopotential Numbers of the Altimetric Network in the Federal District, Brazil}

The Federal District region, in Brazil, between $48.25^{\circ} \mathrm{W}$ and $47.33^{\circ} \mathrm{W}$ and $15.45^{\circ} \mathrm{S}$ and $16.06^{\circ} \mathrm{S}$ (Figure 2), has a slightly wavy relief, ranging from 600 to 1340 meters above sea level. Several works on territorial planning have been carried out over time due to the continuous development of the region, among them, the implementation of a precision altimetric network to elaborate and update the cartographic and cadastral basis, and the execution of infrastructure projects as well. Despite having 136 stations distributed throughout the studied region, this network, known as RN-DF (Figure 2), is concentrated in urban and urban expansion areas. In addition to the mentioned stations, the RN-DF incorporates another 30 existing HPAN / IBGE stations, here called RN-IBGE, and 34 stations of the Planimetric Network (SAT-IBGE) (Figure 2), both members of the BGS. The main objective of using the BGS stations was to improve the spatial distribution of altimetric data in the region.

In 2016, the Federal District Development Company (TERRACAP) used the geometric leveling technique and conducted an altimetric survey of the 200 mentioned stations, from RN-DF, RN-IBGE, and SAT-IBGE. This survey required relative datum defined in specific RN-IBGE stations; implementation of altimetric safety points (RNPI-DF) with distance up to $2 \mathrm{~km}$ (Figure 2) within each leveling circuits; measurements of height differences at horizontal distances less than $100 \mathrm{~m} \pm 20 \mathrm{~m}$; use of ground support for positioning the leveling rod; measurements on the leveling rod $50 \mathrm{~cm}$ above the ground; double sections of leveling rod measurements, with direct and inverted position, changing the equipment position for each section; survey in closed circuits; and closure error smaller than $6 \mathrm{~mm}$. $\mathrm{km}^{0.5}$. The altimetric survey used calibrated and certified Leica DNA3 digital levels and was conducted in 2016.

Figure 2 shows the data cited above that was used for estimating normal heights and geopotential numbers. The 728 RNPI-DF points (Figure 2) show the paths covered, comprising $1393 \mathrm{~km}$ of geometric leveling performed in 58 circuits for the 200 points considered in this study.

In addition to altimetric data, the region (Figure 3) has 1377 Ground Gravity Stations (GGS) provided/managed by the BGS/IBGE, the National Petroleum Agency (ANP) and the University of Brasilia (UnB). The GGS provided by the IBGE and ANP were acquired using the LaCoste \& Romberg and Scintrex Autograv CG-5 gravity meter between 1990 and 2014. However, the GGS provided by the UnB were acquired using only the Scintrex Autograv CG-5 gravity meter between 2013 and 2017.

The GGS data were used to generate a map of Bouguer anomalies $\left(A_{B g}\right)$, shown in Figure 3. The anomalies, 
which represent the varying physical properties of the rocks in the region, vary from $-103,290$ mGal to $-130,702$ $\mathrm{mGal}$, and were used to estimate gravity values $(g)$ for stations or points that did not have that information.

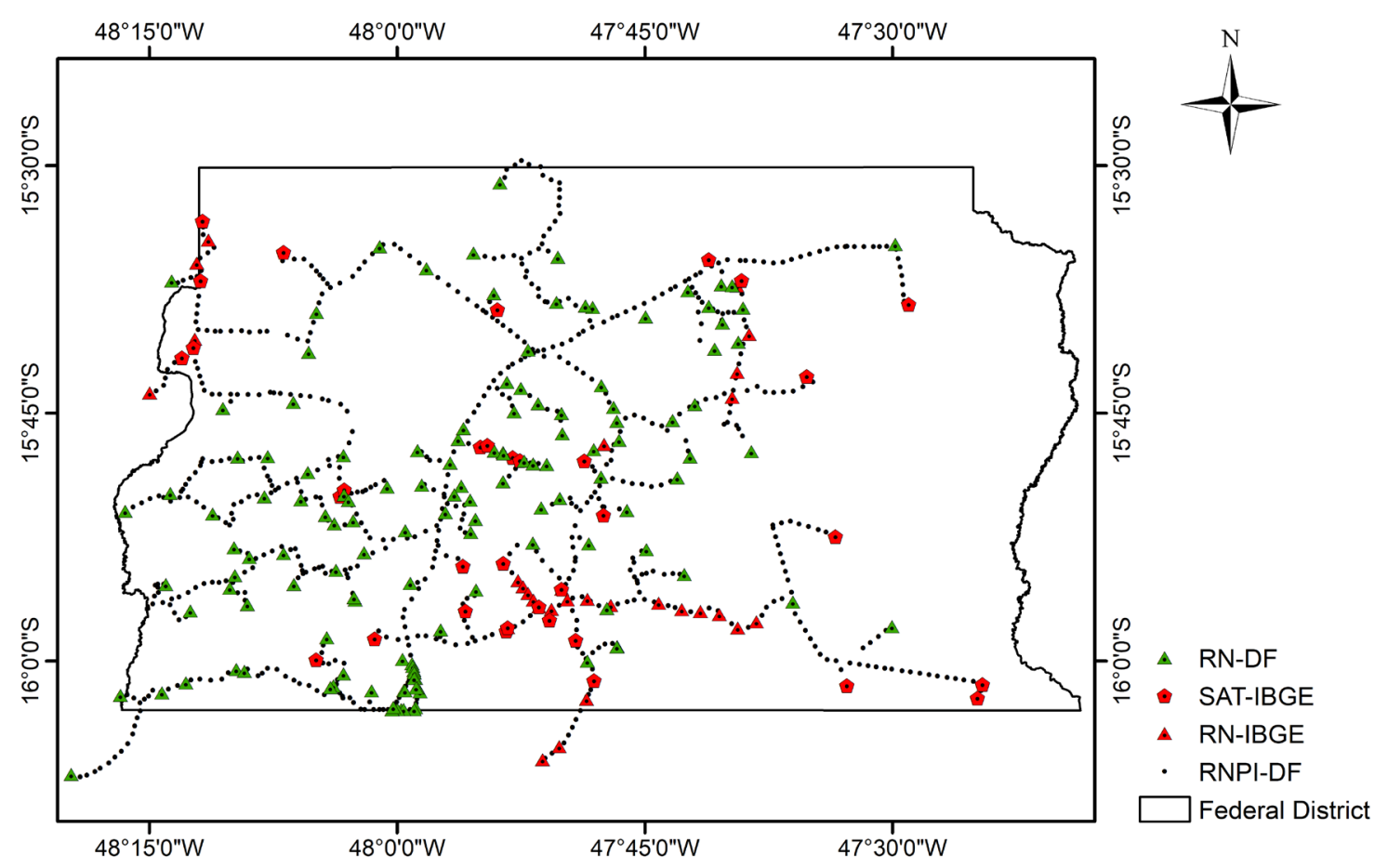

Figure 2: Distribution of the altimetric (RN-DF, RN-IBGE, SAT-IBGE, and RNPI-DF) stations in the study area.

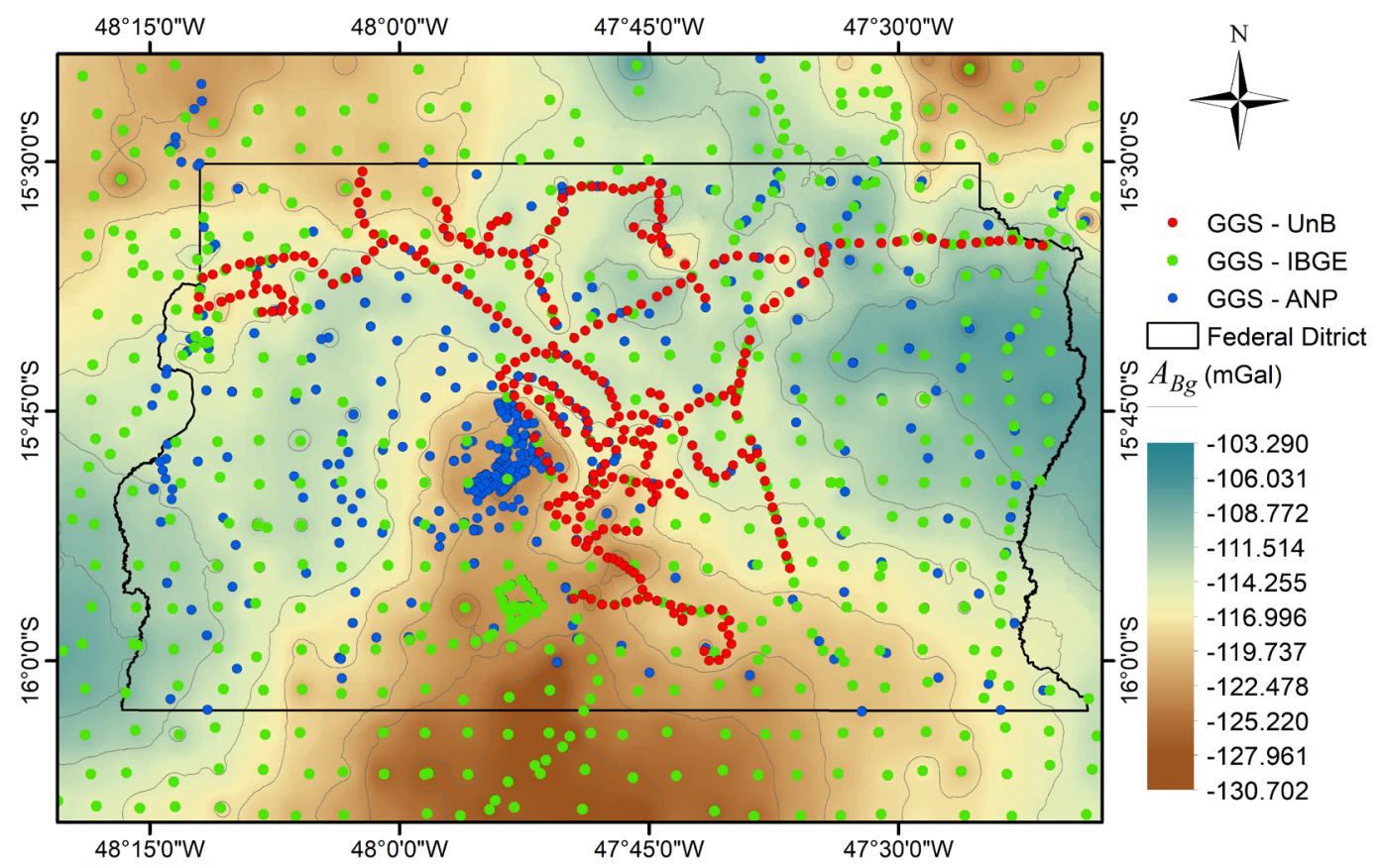

Figure 3: Bouguer anomaly and distribution of gravimetric (GGS) stations provided by IBGE, ANP, and UnB, in the study area. 


\subsection{Computational procedure}

All routines used in this research were implemented based on the MATLAB ${ }^{\circledR}$ software. The flowchart detailing the computation sequence and generation of results is shown in Figure 4. ID (Figure 4) is the identifier of the Backsight and Foresight points ( $B S$ and $F S$ ), which represent the first and last readings, respectively, for each leveling section.

The flowchart in Figure 4 indicates that the information used in this research was separated into reference data, geometric leveling data, and gravity and position data.

The reference data comprises information from stations used as relative datum for computing the heights of the stations of interest. This information includes the identifier, or the name of the station, the geodetic coordinates, the normal heights, the geopotential numbers, and the gravity values. In the first moment, a single reference station (relative datum) was defined, both for computing a priori heights and for the final adjustment of the normal heights and geopotential numbers of the stations of interest. Subsequently, after analyzing the uncertainties of the final results, other reference stations were defined to improve accuracy. The uncertainties used for each reference station were extracted from the HPAN reports.

The geometric leveling data consists of information that allows computing the heights for the points of interest, starting from the reference stations. This information includes the identifier of the backsight $(B S)$ and foresight ( $F S$ ) points, the horizontal distance $(D)$ between $B S$ and $F S$, and height difference $(\Delta H)$. First, the heights and closure errors were computed. The errors were compared with the established tolerance value $(6 \mathrm{~mm}$. $\mathrm{km}^{0.5}$ ). After determining that the closure errors were within the tolerance interval, the normal heights, with their uncertainties, and geopotential numbers were adjusted.

The gravity and position data include information about all points used (RN-DF, RN-IBGE, SAT-IBGE, and RNPIDF), including their respective identifier, geodetic coordinates, and gravity values. In the stations or points lacking gravity values $(g)$, they were computed by interpolating the computed $A_{B g}$ values, using the values of ground gravity stations (Figure 3 ), adopting the following relationship:

$$
\begin{gathered}
A_{B g}=g+C_{F a}+C_{B g}-\gamma \\
C_{F a}=0.3086 H \\
C_{B g}=-2 \pi \rho G H
\end{gathered}
$$

where $\rho$ is the average density of the Earth crust $\left(2.67 \mathrm{~g} . \mathrm{cm}^{-3}\right) ; G$, the gravitational constant of Newton (6.67428e-11 $\left.\mathrm{m}^{3} \mathrm{Kg}^{-1} \mathrm{~S}^{-2}\right) ; C_{F a}$, the free-air correction; $C_{B g}$, the Bouguer correction; and $\gamma$, the normal gravity value.

Interpolation was performed using the Inverse distance weighting (IDW) method applied to the computed $A_{B g}$ values. This data interpolation procedure is commonly adopted to compute geoid models and was used by Marotta and Vidotti (2017).

The height data computed using the reference stations, geometric leveling data and $g$ computed, was also used $a$ priori to compute $\gamma_{v}$, according to the flowchart in Figure 4.

With the requested data (Figures 2 and 3 ), as described in the previous sections, it was possible to estimate the values of $H_{N}, \Sigma_{H_{N}}$ and $C$ for stations and points of interest (Figure 4).

In this research, the GRS80 ellipsoid was used as a reference, and all the constants used, inherent to the presented equations, were given by Moritz (1984) and Petit and Luzum (2010). 


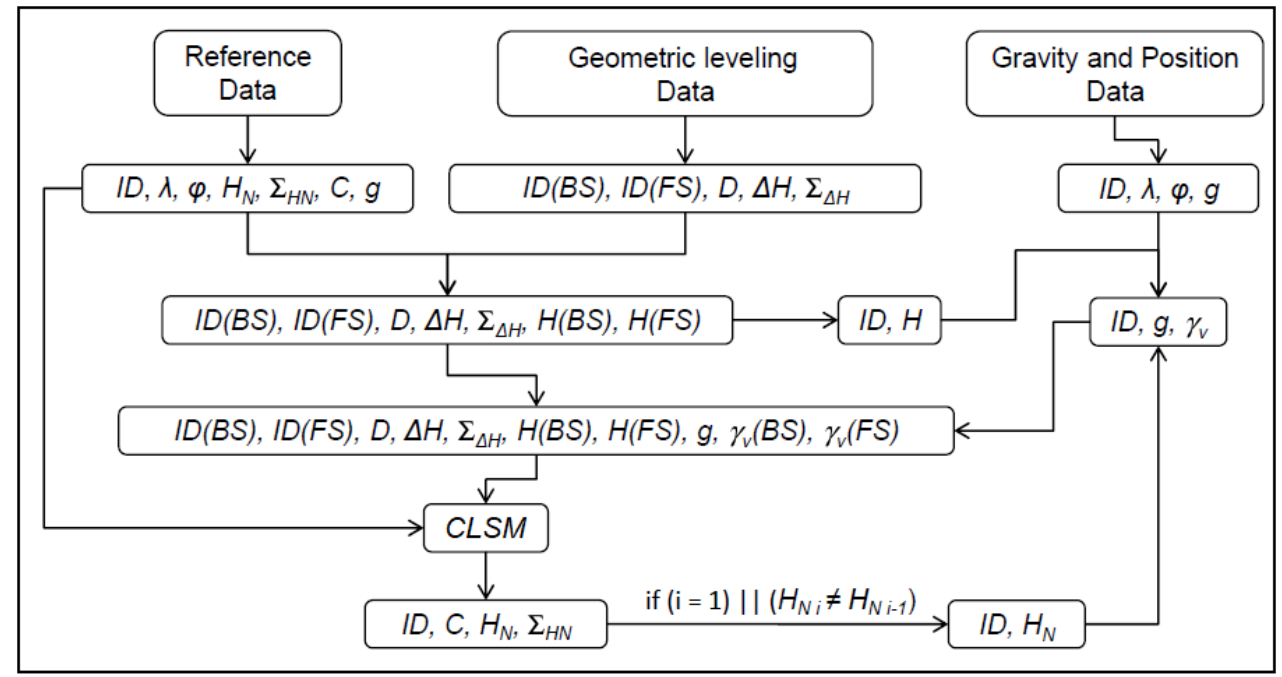

Figure 4: Flowchart of the sequence to estimate $H_{N}, \Sigma_{H_{N}}$ and $C$.

\subsection{Results}

Figure 5 shows the adjustment results of the altimetric network of the Federal District using the uncertainties of $H_{N}$ values estimated for all used stations and points (RN-DF, RN-IBGE, SAT-IBGE, and RNPI-DF), and taking the RN-IBGE station, 2223S, as reference. This station was chosen as a reference because it was the origin of the observations in the geometric leveling survey.

Considering the uncertainties of the $H_{N}$ values estimated by the CLSM, which vary from $0.000 \mathrm{~m}$ to $0.037 \mathrm{~m}$ (Figure 5), it can be seen that the stations and points farthest from the reference station (RN-IBGE 2223S) have less accurate results. For this reason, other reference stations were defined to improve the accuracy of the results for the whole study area. This choice considered this station as the origin of the observations, in the geometric leveling

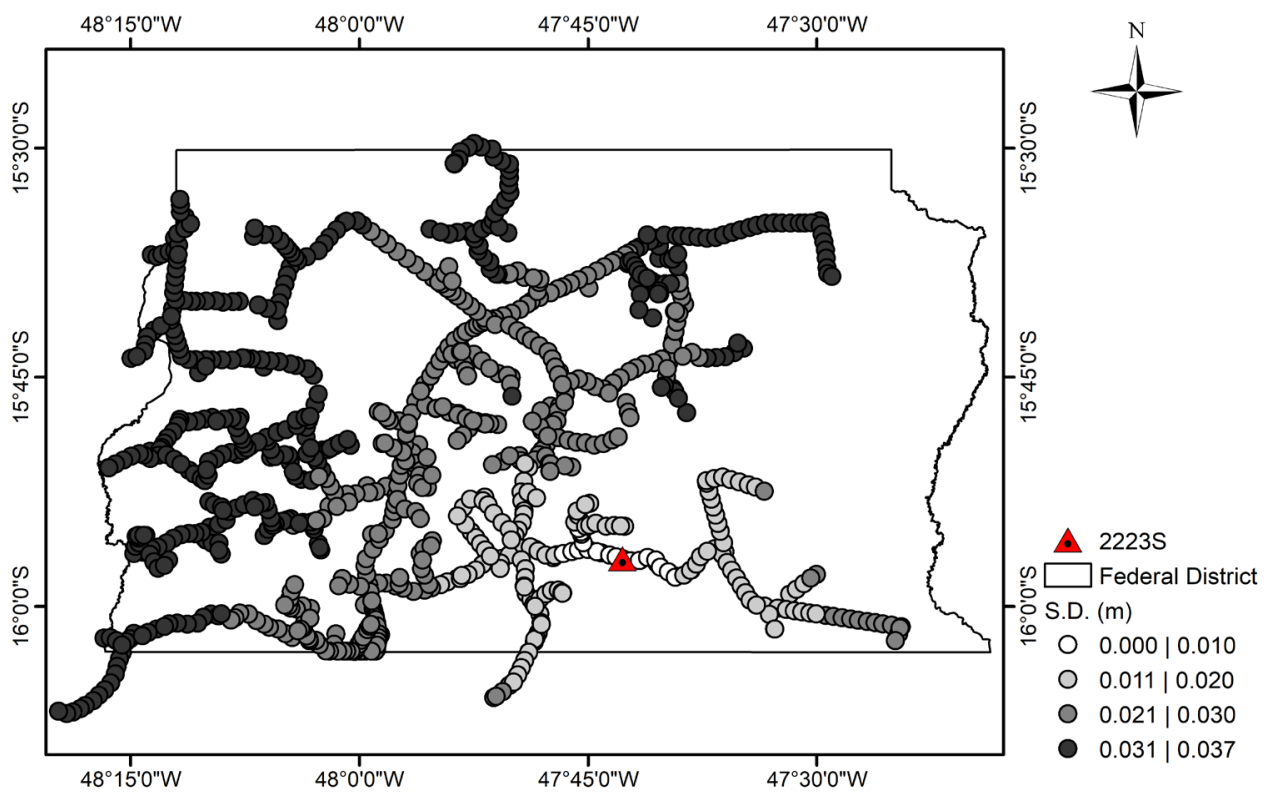

Figure 5: Standard deviations (S.D.) of the $H_{N}$ values estimated for the stations and points used (RN-DF, RN-IBGE, SAT-IBGE, and RNPI-DF), using the 2223S RN-IBGE station as reference. The black polygon corresponds to the geographic boundary of the Federal District. 
survey (RN-IBGE 2223S), and stations located in the central region of the study area (RN-IBGE 9305U) and/or that were used in more extensive and distant circuits (RN-IBGE 2263Z). Additionally, the differences between computed and known $H_{N}$ were smaller than the uncertainties estimated for all selected reference stations.

On the applied CLSM performance, the $\bar{\sigma}_{0}^{2}$ estimated (0.158) was out of the $\chi^{2} / g l$ range (0.888 to 1.119) defined for 578 degrees of freedom $(g l)$ at $95 \%$ confidence level. As the $\hat{\sigma}_{0}^{2}$ was less than the $\chi^{2} / g l$ lower limit and considering the absence of errors in the adopted procedures, it was suggested that the weight of the observations was underestimated. Therefore, the $\hat{\sigma}_{0}^{2}$ was used to compute the standard deviation of the estimated parameters.

After applying the CLSM, the maximum residual value was $0.011 \mathrm{~m}$. Also, the maximum a posterioristandardized residual value was 3.502, smaller than the critical $\tau$ value (4.118) defined for $578 \mathrm{gl}$ at $95 \%$. Therefore, it was concluded that the observations used in this work did not present substantial errors.

Figure 6 shows the $H_{N}$ estimated for the altimetric network, considering the stations 2223S, 9305U and $2263 Z$ of the RN-IBGE as reference. Figure 7 shows the uncertainties of the $H_{N}$ values ranging from $0.000 \mathrm{~m}$ to $0.032 \mathrm{~m}$ whereas Figure 8 shows the $C$ computed directly, according to Equation 5 , using computed $\gamma_{v}$ (Equation 6) and estimated $H_{N}$, shown in Figure 6.

The results in Figures (5) and (7) show that the position and spatial distribution of the reference stations affected significantly the estimation of the uncertainties of the estimated $H_{N}$ values.

The $H_{N}$ values estimated using the three reference stations (2223S, 9305U and 2263Z) were compared with known values (Tables 1, 2 and Figure 9), according to IBGE (2018). The results for the 27 stations analyzed show that the differences (Table 1 ) range from $0.119 \mathrm{~m}$ to $-0.307 \mathrm{~m}$, with $-0.008 \mathrm{~m}$ average and $0.102 \mathrm{~m}$ root-mean-square deviation (Table 2). Also, the largest differences between $-0.124 \mathrm{~m}$ (2226R) and $-0.308 \mathrm{~m}$ (1361T) are concentrated in the northeastern region of the studied area (Figure 9), close to the $9305 \mathrm{U}$ station (used as reference), in approximately $15 \mathrm{~km}$ stretch of a geometric leveling circuit. In addition, the differences varied from $0.003 \mathrm{~m}$ to $0.118 \mathrm{~m}$ (Table 1 ) in stations (Figure 9) located near to $2223 \mathrm{~S}$ (used as a reference).

Despite the large differences in the $H_{N}$ values (Tables 1, 2 and Figure 9), the geometric leveling performed and used in this research was consistent. This result is firstly explained by the fact that all 58 circuits adjusted together, contemplating $30 \mathrm{RN}-$ IBGE stations, $136 \mathrm{RN}-\mathrm{DF}$ stations, 34 SAT-IBGE stations, and $1393 \mathrm{~km}$ total length, had differences smaller than $6 \mathrm{~mm}$. $\mathrm{km}^{0.5}$ for each circuit and, secondly, the residual values and the statistical test applied showed no problems in the observations.

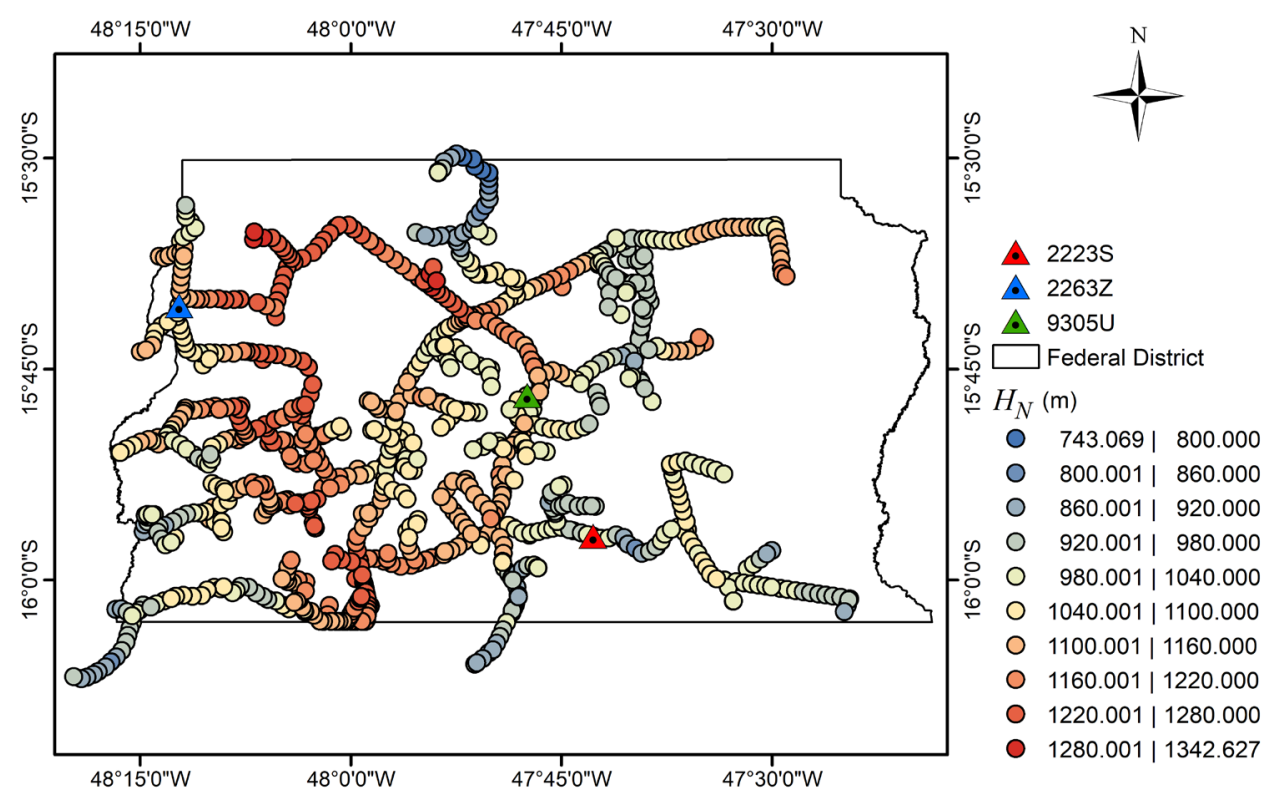

Figure 6: $H_{N}$ values estimated for the stations and points (RN-DF, RN-IBGE, SAT-IBGE, and RNPI-DF), using stations 2223S, $2263 Z$ and $9305 \mathrm{U}$ of the RN-IBGE as reference. 
Furthermore, it is noteworthy that between 1953 and 2005, 256 RN-IBGE stations were implanted within the Federal District limits, close to roads that have been maintained or expanded along the years. And, according to IBGE information, only 70 out of 256 stations were considered in good conditions between 1995 and 2011 while the others were either destroyed or not found. In 2016, at the time of this research, only thirty out of 70 stations were found and used because they had reliable planimetric coordinate values estimated by GNSS positioning. Also, as described, it is possible that some of the RN-IBGE stations had their original positions changed, being, therefore, advisable to conduct a rigorous analysis of these stations by investigating the original leveling data measured by IBGE or by repeating some leveling circuits, including the stations with large differences between $H_{N}$ as determined in this work.

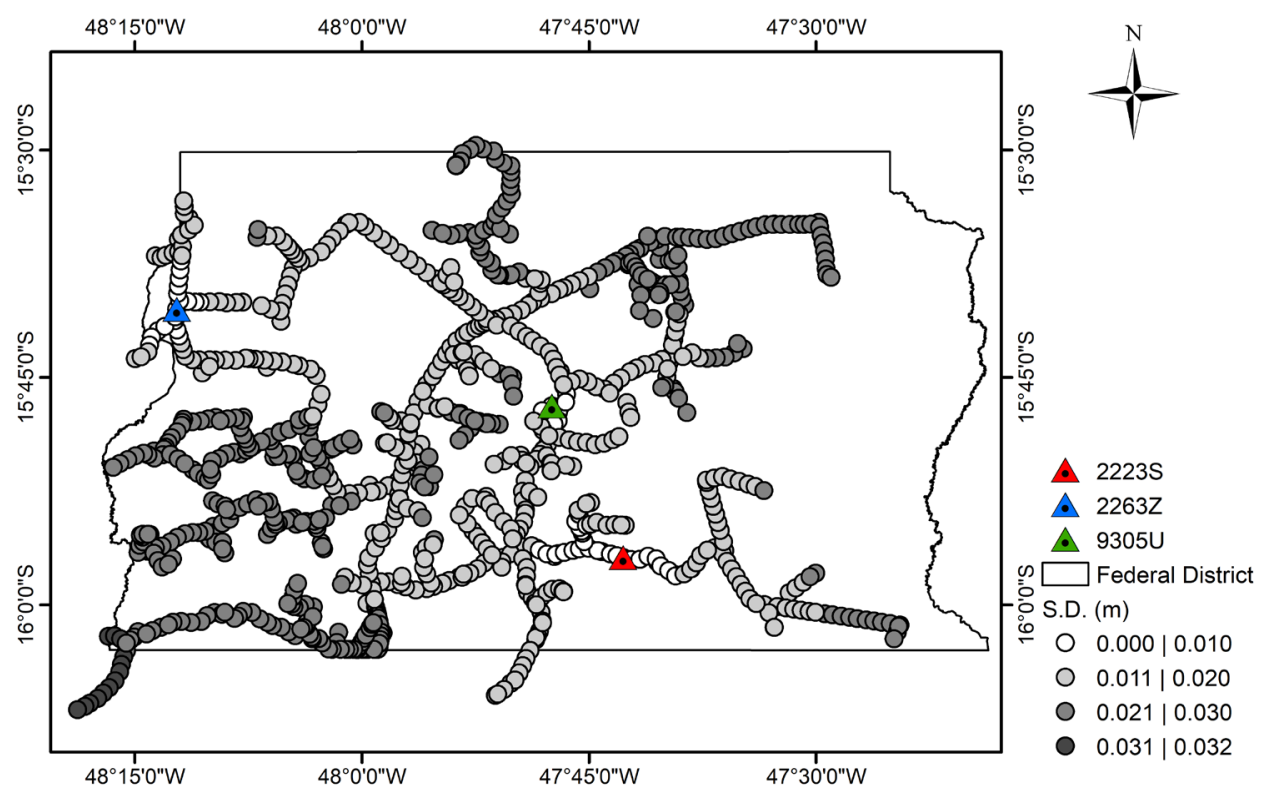

Figure 7: Standard deviations (S.D.) of the $H_{N}$ values estimated for the stations and points (RN-DF, RN-IBGE, SATIBGE, and RNPI-DF), taking the stations 2223S, $2263 Z$ and $9305 \mathrm{U}$ of the RN-IBGE as reference.

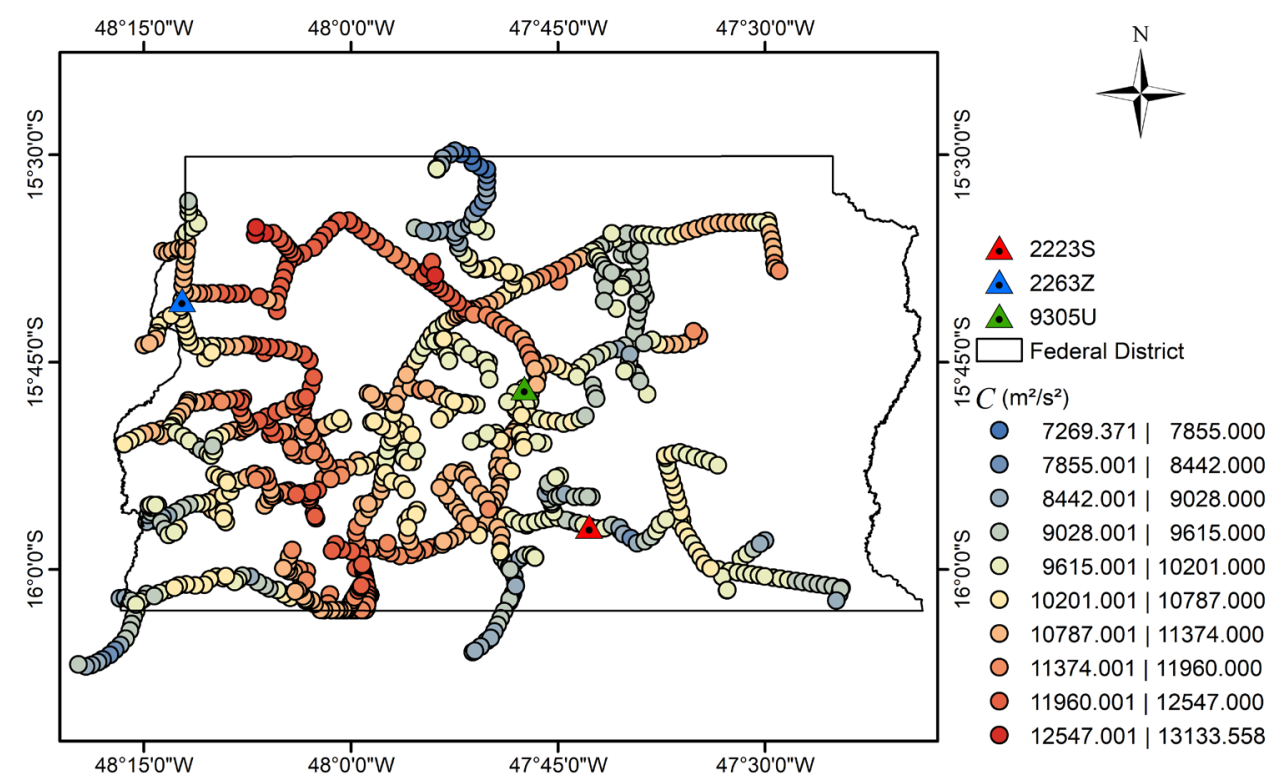

Figure 8: computed using $H_{N}$ values estimated for the stations and points (RN-DF, RN-IBGE, SAT-IBGE, and RNPI-DF). 
Table 1: Differences between the $H_{N}$ estimated values, according to the adjustment considering the reference stations $2223 \mathrm{~S}, 2263 Z$ and $9305 \mathrm{U}$, and known values $\left(H_{N I B G E}\right)$ for the RN-IBGE stations used.

\begin{tabular}{|c|c|c|c|c|c|c|c|}
\hline \multirow{2}{*}{$\begin{array}{l}\text { Station } \\
1190 D \\
\end{array}$} & \multirow{2}{*}{$\begin{array}{c}\begin{array}{c}\text { Longitude } \\
\left({ }^{\circ}\right)\end{array} \\
-47.808611 \\
\end{array}$} & \multirow{2}{*}{$\begin{array}{c}\begin{array}{c}\text { Latitude } \\
\left({ }^{\circ}\right)\end{array} \\
-16.038611 \\
\end{array}$} & \multicolumn{2}{|c|}{$\begin{array}{c}H_{N I B G E} \\
(\mathrm{~m})\end{array}$} & \multicolumn{2}{|c|}{$\begin{array}{l}H_{N} \\
\text { (m) }\end{array}$} & \multirow{2}{*}{$\begin{array}{c}H_{N}-H_{N I B G E} \\
(\mathrm{~m}) \\
0.027\end{array}$} \\
\hline & & & 935.906 & \pm 0.071 & 935.933 & \pm 0.016 & \\
\hline $1190 \mathrm{G}$ & -47.836111 & -16.086389 & 886.558 & \pm 0.071 & 886.536 & \pm 0.019 & -0.023 \\
\hline $1190 \mathrm{H}$ & -47.852778 & -16.099444 & 924.429 & \pm 0.071 & 924.471 & \pm 0.019 & 0.042 \\
\hline $1361 \mathrm{~T}$ & -47.672385 & -15.620219 & 961.315 & \pm 0.070 & 961.008 & \pm 0.022 & -0.307 \\
\hline $2223 M$ & -47.807511 & -15.937747 & 1041.224 & \pm 0.071 & 1041.251 & \pm 0.010 & 0.027 \\
\hline $2223 N$ & -47.784167 & -15.943889 & 1010.868 & \pm 0.071 & 1010.867 & \pm 0.009 & -0.001 \\
\hline $2223 R$ & -47.735833 & -15.941667 & 971.820 & \pm 0.071 & 971.823 & \pm 0.006 & 0.003 \\
\hline $2223 T$ & -47.693611 & -15.950000 & 990.627 & \pm 0.071 & 990.615 & \pm 0.005 & -0.012 \\
\hline $2223 U$ & -47.674444 & -15.953056 & 867.690 & \pm 0.071 & 867.626 & \pm 0.008 & -0.064 \\
\hline $2223 \mathrm{~V}$ & -47.655833 & -15.966667 & 897.657 & \pm 0.071 & 897.621 & \pm 0.010 & -0.036 \\
\hline $2223 X$ & -47.636952 & -15.960361 & 964.086 & \pm 0.071 & 964.053 & \pm 0.011 & -0.033 \\
\hline $2226 N$ & -47.661611 & -15.733908 & 923.904 & \pm 0.071 & 923.756 & \pm 0.019 & -0.148 \\
\hline $2226 \mathrm{R}$ & -47.656389 & -15.708611 & 971.788 & \pm 0.071 & 971.664 & \pm 0.019 & -0.124 \\
\hline 2230 & -47.656667 & -15.621389 & 950.450 & \pm 0.070 & 950.305 & \pm 0.022 & -0.144 \\
\hline $2263 N$ & -48.249444 & -15.729444 & 1158.403 & \pm 0.074 & 1158.382 & \pm 0.011 & -0.022 \\
\hline 2264D & -48.201944 & -15.598333 & 1062.287 & \pm 0.075 & 1062.338 & \pm 0.012 & 0.051 \\
\hline $2264 \mathrm{~F}$ & -48.190000 & -15.575000 & 1013.240 & \pm 0.075 & 1013.286 & \pm 0.014 & 0.046 \\
\hline $2377 \mathrm{H}$ & -47.856667 & -15.945278 & 1141.577 & \pm 0.071 & 1141.681 & \pm 0.013 & 0.104 \\
\hline $2377 \mathrm{P}$ & -47.888056 & -15.966389 & 1137.062 & \pm 0.071 & 1137.179 & \pm 0.015 & 0.116 \\
\hline $2378 \mathrm{~A}$ & -47.877500 & -15.918889 & 1146.738 & \pm 0.071 & 1146.824 & \pm 0.015 & 0.086 \\
\hline $2378 B$ & -47.872500 & -15.925000 & 1148.820 & \pm 0.071 & 1148.855 & \pm 0.015 & 0.036 \\
\hline $2378 C$ & -47.867500 & -15.931667 & 1152.090 & \pm 0.071 & 1152.191 & \pm 0.014 & 0.101 \\
\hline $2378 \mathrm{D}$ & -47.862222 & -15.938333 & 1151.760 & \pm 0.071 & 1151.854 & \pm 0.014 & 0.094 \\
\hline $4023 \mathrm{~A}$ & -47.843889 & -15.947778 & 1124.923 & \pm 0.071 & 1125.001 & \pm 0.012 & 0.078 \\
\hline 4023B & -47.827839 & -15.938263 & 1148.282 & \pm 0.071 & 1148.400 & \pm 0.011 & 0.119 \\
\hline $4032 \mathrm{~J}$ & -47.833611 & -15.927500 & 1167.752 & $*$ & 1167.707 & \pm 0.011 & -0.045 \\
\hline $9025 \mathrm{U}$ & -47.644444 & -15.670278 & 925.112 & \pm 0.071 & 924.914 & \pm 0.020 & -0.198 \\
\hline
\end{tabular}

*represents unreported value.

Table 2: Descriptive statistics of the differences between the $H_{N}$ estimated values, according to the adjustment considering the reference stations 2223S, $2263 Z$ and 9305U, and known values $\left(H_{N I B G E}\right)$ for the RN-IBGE stations used.

Statistics

\section{Maximum Value $(\mathrm{m})$}

Minimum Value $(\mathrm{m})$

Average Value $(\mathrm{m})$

Minimum Absolute Value $(\mathrm{m})$

Maximum Absolute Value $(\mathrm{m})$

Root-mean-square deviation Value $(\mathrm{m})$

$$
H_{N}-H_{N I B G E}
$$

\subsection{9}

$-0.307$

$-0.008$

0.001

0.307

0.102 


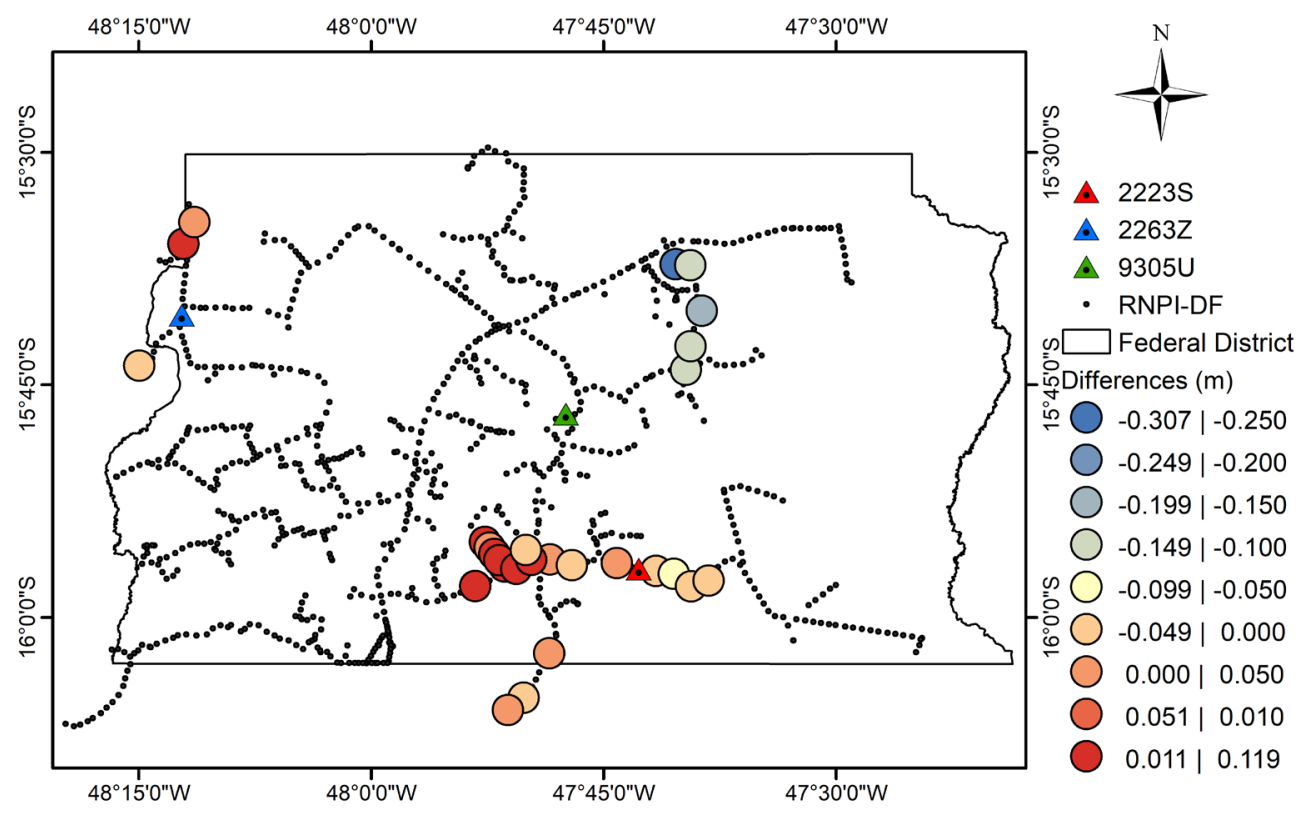

Figure 9: Spatial distribution of the differences between the $H_{N}$ estimated values, according to the adjustment considering the reference stations 2223S, $2263 Z$ and 9305U, and known values for the RN-IBGE stations used.

\section{Conclusion}

This work presents procedures adopted for adjusting, using the geometric leveling, and estimating the normal heights and geopotential numbers for stations and points that are part of the Altimetric Network of the Federal District, Brazil.

The results show good accuracy of the estimated normal height values. Spatially, the accuracy increased (ranging from $0.000 \mathrm{~m}$ to $0.032 \mathrm{~m}$ ) as the number of stations used as reference to compute the normal heights also increased.

Large differences were observed in the results when comparing the normal height values estimated in this research with the known values established by IBGE (2018). It is also observed that the greatest differences were concentrated in specific regions of the study site, in approximately $15 \mathrm{~km}$ stretch of a geometric leveling circuit located near to one station used as a reference.

Despite the large differences in the normal height values, the geometric leveling performed and used in this research was consistent. This result is firstly explained by the fact that all 58 circuits adjusted together, contemplating 30 RN-IBGE stations, 136 RN-DF stations, 34 SAT-IBGE stations, and $1393 \mathrm{~km}$ total length, with differences smaller than $6 \mathrm{~mm} . \mathrm{km}^{0.5}$ for each circuit and, secondly, the residual values and the applied statistical test indicated no problems in the observations. Therefore, in the Federal District, it is suggested to use the normal heights and geopotential numbers computed in this research for the RN-DF stations, to meet internal demands. However, due to the large differences detected in the RN-IBGE stations in this study, it is also recommended to conduct a rigorous analysis of the original leveling data measured by IBGE or to repeat some leveling circuits, including those stations with detected large differences between normal heights.

\section{ACKNOWLEDGMENT}

TERRACAP, for providing the raw data of geometric levelling; IBGE, for providing data of stations and information 
about the HPAN; IBGE, BDEP/ANP and UnB (Profa. Roberta Mary Vidotti), for providing the ground gravity data; and FAPDF (0193.001230/2016 and 0193.001230/2016) and INCTET (465613/2014-4), for financial support.

\section{AUTHOR'S CONTRIBUTION}

The author has developed all the work.

\section{References}

Cross, P. A. 1983. Advanced least squares applied to position-fixing: Working Paper n. 6. 1th ed. North East London Polytechnic.

Drewes, H. et al. 2002. Scientific Foundations of the SIRGAS Vertical Reference System. Vertical Reference System VeReS, Springer, Berlin, pp. 197-301.

Freitas, S. R. C. and Blitzkow, D. 1999. Altitudes e geopotencial. IGeS Bulletin-Special Issue for South America, 9, pp. 47-62.

Gemael, C. 1999. Introdução à Geodésia Física. Curitiba: Editora UFPR.

Heiskanen, W. A. and Moritz, H. 1967. Physical Geodesy, San Francisco: W.H. Freeman and Co.

IBGE - Instituto Brasileiro de Geografia e Estatística. 2018. Reajustamento da Rede Altimétrica com Números Geopotenciais - Relatório. Available at: <ftp://geoftp.ibge.gov.br/informacoes_sobre_posicionamento_geodesico/ rede_altimetrica/relatorio/relatorio_REALT_2018.pdf> [Accessed 10 December 2018].

Luz, R. T. 2004. Possibilidades de integração de dados gravimétricos à rede altimétrica do SGB para cálculo de altitudes SIRGAS no Brasil. Série em Ciências Geodésicas, 4, 42 pp.

Luz, R. T. 2016. Cálculo de altitudes científicas e sua aplicação no reajustamento da rede altimétrica de alta precisão do sistema geodésico brasileiro. Revista Brasileira de Geografia, 61, pp. 79-97.

Marotta, G. S. and Vidotti, R. M. 2017. Development of a local geoid model at the federal district, Brazil, patch by the Remove-Compute-Restore technique, following Helmert's condensation method. Boletim de Ciências Geodésicas, 23(3), pp. 520-538.

Moritz, H. 1984. Geodetic Reference System 1980. Buletin géodésique, 58(3), pp. 388-398.

Palmeiro, A. S. and Freitas, S. R. C. 2010. Integração de informações do SGB em um SIG, visando a realização do sistema vertical do SIRGAS. Boletim de Ciências Geodésicas, 16, pp. 365-385.

Petit, G. and Luzum, B. 2010. IERS Conventions. IERS Technical Note № 36. Verlag des Bundesamts für Kartographie und Geodäsie.

Severo, T. C. et al. 2013. Estudo das correções gravimétricas para altitudes físicas aplicadas aos desníveis da RAAP. Boletim de Ciências Geodésicas 19, pp. 472-497.

Torge, W. 1991. Geodesy. 2rd ed. Berlin; New York: de Gruyter. 